\title{
Entre movimentos e trajetórias laborais de jovens profissionais
}

\author{
Geruza Tavares D'Avila ${ }^{1}{ }^{1}$ \\ Maria Chalfin Coutinho (102 \\ ${ }^{1}$ Universidade Federal do Rio Grande. Rio Grande, RS, Brasil. \\ ${ }^{2}$ Universidade Federal de Santa Catarina. Florianópolis, SC, Brasil.
}

\begin{abstract}
Resumo
$\mathrm{O}$ artigo resulta de uma investigação doutoral cujo objetivo foi compreender os movimentos laborais e os sentidos atribuídos ao trabalho por jovens profissionais. Entendemos que o processo de ingressar em uma universidade e, posteriormente, no "mundo do trabalho", possui particularidades no Brasil, tensionado entre distintas áreas como a educação, em especial, a de nível superior, e o trabalho. Para o estudo, entrevistamos 16 jovens profissionais recém-formados em cursos noturnos de uma universidade federal. As análises, inspiradas nos Núcleos de Significação, foram realizadas por meio das 1) Marcas sociais; 2) Vivências nos cursos universitários e nos cursos de bacharelado; 3) Trajetórias laborais; e 4) Concepções sobre o trabalho. A partir dos resultados, consideramos que o trabalho, assim como a educação, mediou todo o movimento dos jovens profissionais em direção ao mundo do trabalho. Ademais, em seus processos de inserção profissional, os jovens, diante das dificuldades com as quais se defrontaram, ressignificaram suas concepções e expectativas em relação ao trabalho.
\end{abstract}

Palavras-chave: trabalho, ensino superior, jovens.

\section{Between movements and labor trajectories of young professionals}

\begin{abstract}
The content of this article is from a dissertation which aimed at understanding labor movements and the meanings attributed to work by young professionals. We understand that the process of entering a university and, later on, in the working world, has some particularities in Brazil, bringing tension between distinct areas such as Education, especially Higher Education, and Work. Sixteen young adults who had just recently finished their evening under graduation courses at federal universities were interviewed. The analysis, inspired by the Meaning Core, was made through: 1) Social Marks; 2) Living experiences in college; 3) Labor Trajectories; and 4) Conceptions on "work". Based on the results, we consider work as well as education as mediators of the young professionals" movement towards the world of work. In addition, in their processes of entering the world of work, the young adults, in the face of difficulties, gave new meaning to their conceptions and expectations in relation to work.
\end{abstract}

Keywords: labour, higher education, young adults.

\section{Entre movimientos y trayectorias laborales de los jóvenes profesionales}

\section{Resumen}

El artículo resulta de una investigación doctoral, cuyo objetivo ha sido comprender los movimientos laborales y los sentidos atribuidos al trabajo por jóvenes profesionales. Entendemos que el processo de ingressar en una universidad y, posteriormente, en el "mundo del trabajo", posee particularidad en Brasil, tensado entre distintas áreas como la Educación, en especial la de nivel Superior, y el Trabajo. Entrevistamos a 16 jóvenes profesionales recién graduados en cursos nocturnos de una universidad federal. Los análisis inspirados en los Núcleos de Significación se realizaron por medio de las 1) Marcas Sociales, 2) Vivencias en los cursos universitarios y los cursos de bachillerato, 3) Trayectorias Laborales y 4) concepciones sobre el trabajo. A partir de los resultados inferimos que el trabajo, así como la educación, mediaron todo el movimiento de los jóvenes profesionales hacia el mundo del trabajo. Además, en sus procesos de inserción profesional los jóvenes frente a las dificultades con las que se enfrentaron resignificaron sus concepciones y expectativas en relación con el trabajo.

Palabras clave: trabajo, educación superior, jóvenes. 


\section{Introdução}

Este artigo apresenta a síntese de uma investigação doutoral cujo objetivo foi compreender as relações entre os movimentos laborais e os sentidos atribuídos ao trabalho por jovens profissionais provenientes de formação superior em cursos noturnos. Entendemos que as particularidades da experiência ao longo da graduação compõem os movimentos dos jovens e a produção de sentidos construídas. Ao focar nesse tema, o estudo se situa na articulação entre trabalho e Educação Superior, abrindo espaço para as relações tensionadas entre os dois campos e para as transformações em curso.

Entendemos o trabalho como uma atividade intencional concretizada nas relações entre o homem e a natureza, em que ambos se modificam e são modificados um pelo outro, sendo, destarte, uma relação dialética (Marx, 2010). Partindo da Psicologia Social do Trabalho, esta categoria, além de ser central, deve ser compreendida em sua materialidade e em sua historicidade, conforme apontam Sato, Coutinho e Bernardo (2017).

Nesse sentido, e buscando entender a classe trabalhadora hoje, Antunes $(2014$, p. 39) explica que ela é "resultado de um monumental processo de reestruturação produtiva desencadeado desde os inícios dos anos 1970 nos países centrais, e especialmente desde meados dos anos 1980 nos países do sul". Desta forma, o autor menciona a "heterogeneidade" quanto às formas de ser da classe trabalhadora e aponta, ao mesmo tempo, uma tendência em direção à homogeneidade "que resulta da condição precarizada presente em distintas modalidades de trabalho que se ampliam em várias partes do mundo e também no Brasil" (Antunes, 2014, p. 51).

Logo, tais transformações atingem a todos, mas, em especial, os jovens que buscam inserção laboral (Silva, 2014) e, de forma particular, aqueles que concluem seus cursos superiores (Mattos \& Bianchetti, 2011; Dias \& Soares, 2012). Sendo assim, tanto as transformações ocorridas no mundo do trabalho como os contextos familiar, laboral e acadêmico que o estudante frequenta contribuem para a produção de sentidos do trabalho, assim como a trajetória desenvolvida desde antes dos primeiros anos universitários.

Destacamos ainda, as diversas transformações quanto à ampliação do acesso ao ensino de nível superior ocorrido no Brasil nos últimos anos. Não só a forma de acessar o ensino superior público alterou-,,se, como também o número de vagas nas universidades públicas teve um expressivo aumento. Muitas universidades públicas foram criadas na última década, assim como muitas outras se interiorizaram por meio da construção de novos campi fora de sua cidade-sede. Conforme preconizava o Programa de Apoio a Planos de Reestruturação e Expansão das Universidades Federais - REUNI, instituído pelo Decreto n. 6.096 (2007) havia também a preocupação quanto à oferta de cursos noturnos, pois possibilitariam o ingresso de universitários que trabalham durante o dia. Vargas e Paula (2013) discutem tais transformações, destacando, ainda, como a relação entre educação e trabalho vem sendo desenvolvida em Portugal e em Cuba.

Tendo em vista o contexto acima, no presente estudo investigamos jovens profissionais, isto é, homens e mulheres detentores de um título de bacharelado, que cursaram em período noturno, uma Instituição de Ensino Superior (IES) brasileira. Ainda que políticas públicas delimitem para a juventude a faixa etária entre 15 e 29 anos de idade, (Lei n. 11.129, 2005; Lei n. 12.852, 2013), consideramos "juventudes" em sua pluralidade, tendo em vista que "são construídas em condições sócio-históricas específicas” (Borges, 2017, p. 208).

Partindo, assim, de nossa pergunta de pesquisa quais as relações entre os movimentos laborais e os sentidos atribuídos ao trabalho por jovens profissionais -, apresentaremos as principais definições para as categorias estudadas, as noções de movimentos e as trajetórias laborais em suas articulações com as juventudes e, em seguida, o método e a discussão dos resultados encontrados em nossa pesquisa para, finalmente, sintetizarmos algumas considerações.

\section{A noção de movimento e as trajetórias laborais}

Partimos do princípio de que há uma relação entre os sentidos atribuídos ao trabalho pelos jovens bacharéis e seus movimentos laborais, especialmente os de inserção. O que desejamos analisar, então, são essas relações entre os movimentos e os sentidos atribuídos ao trabalho e como elas vão se configurando para os sujeitos. Para destacar o caráter processual das trajetórias identitárias ou sociais, como fizeram Bessa e Franzói (2017), Coutinho (2009) e Dubar (1998) recorremos ao estudo dos movimentos, a partir de Henri Bergson (2006). Na visão desse filósofo (18591941) movimento guarda relações entre os conceitos de tempo e de espaço, pois sendo um fenômeno observável em um objeto móvel, fica impossível a sua apreensão no momento em que se realiza. Dessa forma, buscamos evidenciar os momentos que compuseram o movimento rumo à inserção profissional dos jovens trabalhadores, levando em consideração a busca do 
sujeito quanto à construção de sua trajetória ao longo de um tempo e espaço específicos, sem esquecer, no entanto, o diálogo com as suas condições materiais de existência.

Para compreender os movimentos laborais dos jovens profissionais, vários autores têm feito uso de diferentes concepções sobre as trajetórias. Conforme Pais, Lacerda e Oliveira (2017) ao analisarmos os percursos juvenis é mister relacionar "escolhas biográficas" e estruturas sociais. Nas palavras dos autores, estas podem ser caracterizadas como espaços onde se desenvolvem as trajetórias e suas escolhas, ainda que "a fuga aos destinos prováveis seja hoje em dia mais plausível do que há algumas décadas, a condição social dos jovens, sua pertença de classe, continuam a pesar na eleição e concretização das suas escolhas biográficas" (Pais, Lacerda, \& Oliveira, 2017, p. 305).

Para Bessa e Franzói (2017, p. 132), apoiados em Claude Dubar, a continuidade ou a ruptura nas trajetórias de trabalho, assim como a coerência com aquelas categorias que em geral são socialmente relacionadas à profissão, dependem de "atos de pertencimento" entre duas transações, "uma biográfica/ subjetiva e outra relacional/objetiva". No campo da Psicologia, Coutinho (2009) enfatiza o uso das trajetórias identitárias como um importante recurso de análise das dimensões subjetivas e objetivas, também ancorada em Dubar, e indica a temporalidade (passado, presente e futuro) como uma forma de investigar os percursos laborais.

Em entrevista publicada sob a forma de artigo (Pais, Lacerda, \& Oliveira, 2017), José Machado Pais ressalta, em relação aos jovens europeus e suas transições entre o mundo da escola e do trabalho, o quanto as condições sociais oportunizam - ou não, a criação de empregos, chamando atenção para o caráter da imprevisibilidade das trajetórias: "temos o misterioso meio, o desconhecido, a imprevisibilidade das curvas e contracurvas de vida que aparecem associadas a tropeços, a itinerários ziguezagueantes, a rumos indefinidos" (Pais, Lacerda, \& Oliveira, 2017, p.305). Tal citação denota a não linearidade com que essas trajetórias - quer sejam laborais, profissionais ou ocupacionais - mostram-se contemporaneamente, em que a não linearidade parece estar cada vez mais em sintonia com a política neoliberal vivenciada pelos diversos atores no contexto brasileiro.

Nesse sentido, as redes de relações sociais fundamentam os movimentos laborais, uma vez que são estabelecidas a partir das vivências dos sujeitos. Sobre as redes de relações sociais, Silva (2010a), partindo de contribuições de alguns teóricos franceses sobre a inserção laboral juvenil em seu diálogo com os seus vínculos pessoais, familiares e institucionais, considera, nesse processo, a profissionalização como central para compreendermos como se constroem os movimentos e as trajetórias laborais.

A profissionalização pode ser definida como o "processo pelo qual certas áreas de competência, delimitadas pela divisão do trabalho são monopolizadas por determinadas categorias de trabalhadores" (Barbosa, 1993, p. 8). Assim sendo, o profissionalismo pode tornar-se um projeto coletivo de mobilidade social tensionado a partir de conhecimentos e saberes em busca do controle de determinado mercado (Barbosa, 1993). Portanto, como o saber começa a adquirir funções sociais diversificadas, é necessária a articulação de uma forma de credenciamento dos diferentes grupos sociais e, logo, amarram-se mercado das profissões e educação. É nesse sentido que Bessa e Franzói (2017) destacaram os "atos de pertencimento" presentes nas transações biográficas e relacionais ao analisarem as trajetórias de duas trabalhadoras com formação técnica no Rio Grande do Sul (RS).

Este pode ser o projeto de mobilidade ao qual se afiliam os jovens profissionais que se dirigem aos bancos escolares do ensino superior no Brasil, ainda que possam ser diversas as razões de busca dos sujeitos pela formação de ensino superior nas mais variadas áreas. Nesse sentido, Silva (2010a, p.245) investigou egressos de três diferentes universidades e o quanto a "inconsistência dos discursos que enaltecem as características escolares como exclusivas para a aquisição de um emprego", uma vez que mesmo com os diplomas universitários o acesso aos empregos depende também do "pertencimento social" destes jovens bem como das condições da "lógica de acumulação capitalista".

Pochmann (2013, p.45) pontua o quanto o conhecimento configura-se como um requisito para inserção laboral dos jovens, considerando a sociedade pósindustrial neste início de século e "a condição diferenciada das juventudes determinada pela renda e relacionada à educação" em nosso país. Deste modo, o autor salienta que para "o exercício do trabalho de qualidade, a conclusão do ensino superior assume cada vez mais relevância, o que exige ingressar mais tardiamente no mercado de trabalho" (Pochmann, 2013, p. 47).

Logo, é preciso destacar, como também fizeram Pais, Lacerda e Oliveira (2017), que as trajetórias juvenis não podem ser compreendidas exclusivamente no seu aspecto individual, como se apenas as problemáticas vocacionais estivessem em jogo. Além disso, cabe lembrar Silva (2010a) ao mencionar que mesmo os jovens mais escolarizados no Brasil não se 
encontram em uma condição de "grandes vantagens", pois além do aumento de jovens diplomados no ensino superior, há uma combinação de "uma política explícita de contenção de gastos adotada pelas grandes empresas, representada não apenas pela dispensa de trabalhadores, mas também pela intensificação da jornada de trabalho e redução salarial" (Silva, 2010a, p.247). Assim, muitos jovens precisam conciliar estudo e trabalho para custear sua permanência universitária. Para as camadas populares, essa conciliação é antecipada, como mostram estudos focados em jovens aprendizes, como o de Mattos e Chaves (2010) realizado no estado da Bahia (BA) e o de Borges (2017) desenvolvido em Santa Catarina (SC).

Em estudo recente realizado no âmbito das IFES do estado do Rio de Janeiro que oferecem cursos noturnos para contemplar a situação do estudante-trabalhador e também do trabalhador-estudante-nos termos cunhados por Marialice Foracchi (1977), as pesquisadoras Vargas e Paula (2013, p. 462) caracterizam a situação enfrentada por alguns estudantes universitários como

[...] pessoas que vivem em situações adversas tais como não possuir geladeira e fogão no domicílio, e possuírem rendimento domiciliar mensal inferior a dois salários mínimos. Esse percentual representa 2,1 milhões de potenciais estudantes que, para serem incluídos no sistema de educação superior dependerão - mais do que da gratuidade - de bolsas de estudo, de trabalho, de monitoria, de extensão, de pesquisa, de restaurantes universitários subsidiados, de moradia estudantil, ou de outras formas que, combinadas a essas, tornem viável a sua permanência no campus.

Como apontado, para a integralização de um curso de nível superior, são necessárias algumas condições mínimas. Os estudantes do período noturno, na "claridade da noite" (Furlani, 2001), geralmente são trabalhadores no período diurno, o que pode dificultar a complementação dos estudos, importantes para quem vivencia o papel de estudante. Nessa direção apontamos as situações amplamente encontradas no ensino noturno, o "estudante-trabalhador" e o "trabalhador-estudante", termos cunhados por Foracchi (1977) e retomados por Sposito (1989) e, mais recentemente, por Vargas e Paula (2013). Nas duas situações, os universitários trabalham matutina e/ou vespertinamente, estudando no período noturno. No primeiro caso, o estudo é principal em relação ao trabalho/emprego, enquanto na segunda situação, isso se inverte, mas nos dois casos tanto o estudo quanto o trabalho podem ocorrer em tempo parcial (Foracchi, 1977; Vargas \& Paula, 2013).
Assim sendo, por mais que as políticas de acesso ao ensino superior tenham possibilitado uma abertura quanto ao ingresso nas universidades brasileiras nos últimos anos, sobretudo nas de iniciativas federais, ainda assim é preciso observar a permanência e a conclusão do curso do estudante que trabalha e do trabalhador que estuda. Segundo Vargas e Paula (2013, p. 464): "É necessário visar com igual ênfase o final do processo: a conclusão, com êxito, dos cursos superiores, incluindo nesses índices as camadas subalternizadas da população". Para isso, não basta "garantir" apenas o acesso: é preciso pensar na situação do jovem antes, durante e depois da universidade.

\section{Método}

A abordagem qualitativa forneceu orientação epistemológica para nossa pesquisa, uma vez que buscamos entender o processo de subjetivação de jovens profissionais em seus movimentos laborais. Assim, consideramos que investigador e investigado são agentes do processo e não há uma posição de neutralidade, mas de proximidade entre sujeito e objeto, constituindo uma relação dialógica e tomando a cultura como produtora e produto da subjetividade (González Rey, 2013).

Desta forma, iniciamos a "etapa exploratória" da pesquisa (Minayo, 2008) em um campus recéminaugurado fora da cidade-sede da universidade. Neste momento, não tínhamos a pretensão de estudar as trajetórias de universitários de cursos noturnos e nem de um curso específico, mas a partir diálogo no campo, nossos interlocutores foram se configurando como egressos dos bacharelados noturnos em Administração, Turismo e Ciências Econômicas.

O levantamento de informações foi realizado, então, mormente no ano de 2012, por meio de entrevistas com 16 bacharéis, nove mulheres e sete homens, com idades entre 23 e 35 anos. A escolha foi realizada por meio do convite da pesquisadora principal - também docente nesse novo campus universitário, aos participantes, previamente indicados por colegas professores e, em alguns casos, pelos próprios interlocutores, uma vez que todos possuíam entre 6 e 12 meses de formados - em geral pertenciam às mesmas turmas. Além da formatura recente, estabelecemos como critério de escolha uma primeira graduação em universidade pública ser considerado como jovem, isto é, estar vivenciando a transição para o mundo produtivo, pois um "dos processos que marcam a transição para a vida adulta é a inserção na vida produtiva" (Mattos \& Chaves, 2010, p. 541). 
Utilizamos um roteiro norteador para as entrevistas $^{1}$, cujas temáticas foram: identificação, escolaridade, universidade e ingresso no mundo do trabalho. Em função do critério de saturação, cuja definição, para Minayo (2008, p. 197-198) corresponde ao "conhecimento formado pelo pesquisador, no campo, de que conseguiu compreender a lógica interna do grupo ou da coletividade em estudo", decidimos interromper o levantamento de novas informações no campo de pesquisa no primeiro semestre de 2013, passando, então, para a análise das transcrições dos áudios gravados.

As análises das entrevistas transcritas foram inspiradas nos Núcleos de Significação sugeridos por Aguiar e Ozella (2013). O processo de análise das informações levantadas culminou com a construção dos Núcleos: 1) Marcas sociais; 2) As vivências universitárias e os cursos de bacharelado, 3) Trajetórias laborais e 4) Concepções sobre o trabalho. A seguir vamos expor os resultados da pesquisa com a apresentação e discussão de cada um deles.

\section{As marcas sociais}

Para responder à pergunta mais geral de nossa pesquisa, foi importante conhecer as redes de relações sociais (Silva, 2010a) dos jovens entrevistados. Assim, iniciamos a análise buscando situar quais momentos marcaram, primordialmente, os entrevistados, em especial pessoas que mediaram suas relações com o processo de trabalho, tendo em vista que "também fisicamente o ser humano deve sua existência ao ser humano" (Marx, 2010, p. 113). A mediação (Vigotsky, 2007), isto é, a relação entre os sujeitos e as vivências, possibilitou a produção dos sentidos do trabalho. Particularmente, alguns sujeitos aparecem com maior intensidade, marcando, então, momentos - para retomar Bergson (2006), particulares de sua trajetória laboral ao longo de um tempo e de um espaço específicos: "só tenho lembrança disso dele [avô materno era marceneiro] que era a única coisa que ficou marcado que eu, que eu vi a oficina dele lá no sítio... (...) trabalhava fazendo móveis mesmo pra, pra várias redes" (Administrador, formado em Administração, 35 anos) $)^{2}$. Conforme González Rey (2013), a cultura é uma produção subjetiva capaz de produzir subjetividades, e além

\footnotetext{
${ }_{1}$ Nossa pesquisa foi submetida e aprovada pelo Comitê de Ética da Universidade onde foi desenvolvido o doutoramento. Todo/as participantes foram informados da pesquisa e assinaram um Termo de Consentimento Livre e Esclarecido (TCLE) antes da realização da entrevista. Os nomes aqui apresentados para cada participante são fictícios e escolhidos no momento das entrevistas.

2 Trechos das transcrições das entrevistas escolhidos para apresentação serão sempre seguidos do nome fictício de cada entrevistado seguido da indicação do curso de bacharelados por ele cursado e a idade.
}

disso, é impossível separá-la dos processos sociais, políticos e/ou econômicos os quais se configuram em todas as vivências e práticas humanas. Assim, em uma dimensão subjetiva podemos dizer que as mediações são capazes de atuar como referências ou marcas, como se convencionou chamar no presente Núcleo de Significação.

Logo, as marcas familiares foram citadas pelos/ as entrevistados/as ao relatarem as histórias familiares desconhecidas, as situações de luto e doenças familiares; as ocupações rurais ou com baixa remuneração das gerações dos avós e dos pais; o desemprego vivenciado pelos pais na infância dos bacharéis; a participação das mães no sustento familiar em situações de desemprego dos pais; as migrações familiares condicionadas pela busca de melhores condições de vida e trabalho; e os sujeitos são a primeira geração de suas famílias a ingressarem na universidade pública. Também foram mencionadas as expectativas dos pais e dos avós quanto ao projeto profissional dos filhos, sobretudo o projeto, não realizado nas gerações anteriores da continuação dos seus estudos. Apresentamos aqui algumas dessas marcas familiares.

O desemprego vivenciado pelos pais na infância dos bacharéis, por exemplo, é comentado por Fernanda (economista, 27 anos) cujo desemprego do pai quando ela era criança, embora afirme não ter considerado "um terror psicológico" junto à família, mas ela prefere usar instabilidade no lugar da palavra desemprego. Sato (2013) também mencionou a dificuldade de desempregados assumirem esta condição. Provavelmente, no processo de construção do ser social, esses fatos contribuíram para os processos de significação em sua vida. Borges (2017) e Dias e Soares (2012) apontam a família como um importante referencial da escolha profissional para os estudantes universitários. A história de desemprego paternal vivenciada pelos entrevistados pode ter sido internalizada pelos sujeitos, que produziram outras significações e formas de se posicionarem diante do mercado de trabalho.

Outra marca familiar se refere aos pais e avós cuja escolaridade é relativamente baixa, configurando uma parte dos entrevistados como a primeira geração de suas famílias a ingressar na universidade. Cabe explicar ainda que, exceto um das entrevistadas cuja formação superior do pai se deu em uma universidade estadual, os pais e mães dos demais entrevistados realizaram o curso superior em universidades privadas e/ou na condição de trabalhadores que estudavam (Foracchi, 1977), sobretudo no ensino noturno, em uma situação muito próxima daquela descrita por Sposito (1989) e, mais recentemente, pelo estudo de Furlani (2001). 
Segundo o discurso de Fernanda (economista, 27 anos), "ele [pai] que pagou a faculdade dele. (...) o meu pai foi melhorar a condição da família dele, entendeu? (...) Minha mãe também, hã, casou, então, ela melhorou de condição".

Aqueles cujos pais ou mães estudaram em universidades públicas relatam que seus progenitores tiveram um longo período de interrupção dos estudos, tendo voltado a estudar após constituírem suas famílias. É o caso relatado por Moisés (administrador, 28 anos): "minha mãe acho que foi a única [na família], foi, já tinha cinquenta anos cursou, fez, fez uma graduação aí fez a pós e agora tá tentando o mestrado também... meus tios também a maioria não concluiu". Esse resultado é similar ao perfil do estudante universitário participante do estudo de Zago (2006), em que a escolaridade da maioria dos pais e das mães correspondeu ao Ensino Fundamental (EF). Larissa (administradora, 24 anos) é a única a mencionar o contrário, pois, além de seus pais, ela enuncia: "todos meus tios hoje em dia têm ensino superior".

Em relação às marcas da escolarização, identificamos a busca pela qualidade do ensino dos filhos pela frequência em escolas consagradas ou na realização do ensino de nível técnico (ET), além da articulação entre o estudo e o trabalho ao longo do ensino fundamental e mensino médio. Já as trajetórias estudantis dos jovens entrevistados, ainda que apresentem alguma descontinuidade em seus movimentos, parecem apresentar certa continuidade, situação apontada por Silva (2010a), mas também por Bessa e Franzói (2017).

\section{Vivências universitárias e os cursos de bacharelado}

As vivências universitárias ao longo dos cursos de bacharelado foram consideradas pelos jovens entrevistados como uma referência em suas vidas, isto é, mais uma marca social produzida, além das marcas familiares e estudantis. Logo, este Núcleo de Significação pode ser visto como um desdobramento do primeiro, em que identificamos algumas similaridades nessas vivências, mas também com algumas distinções em cada um dos cursos de bacharelado investigados e nas vivências de cada jovem. Ademais, após o período do curso de graduação, os entrevistados ressaltaram o desejo de retornar aos bancos escolares, em nível de pós-graduação. Assim sendo, serão apresentados e analisados os principais achados, sendo o primeiro deles a universidade como "um marco" na vida dos jovens.

Quanto às semelhanças vivenciadas pelos jovens profissionais durante suas graduações, foram destacados os cursinhos realizados antes dos processos seletivos das universidades, o exame vestibular; a busca pelas universidades públicas; a escolha profissional e da universidade; o ingresso no campus recém-inaugurado; e ser trabalhador e estudante, ao mesmo tempo, dentro da universidade. Todos esses indicadores configuram as vivências dentro da universidade como um "marco" em suas trajetórias, transformando suas concepções sobre a vida de uma maneira geral, tal como mencionaram Dias e Soares (2012).

Um primeiro ponto destacado refere-se ao acesso dos jovens às IES, notadamente à recorrência dos candidatos aos processos seletivos das universidades brasileiras em busca de cursinhos pré-vestibulares. Todos os entrevistados submeteram-se aos Exames Vestibulares em mais de uma instituição, além da universidade cursada. Além disso, a escolha pela universidade dependeu de uma série de fatores, mas notamos as condições da família e das escolas em que estudaram no ensino médio ou mesmo de pessoas participantes de suas relações sociais que possibilitaram informações sobre o novo campo em que estavam a ingressar. Nenhum deles, por outro lado, mencionou o porquê de a universidade pública ser considerada "o alvo" pelos estudantes, além da questão de uma suposta qualidade do ensino nessas organizações e pelo fato de o ensino ser gratuito. Assim, percebemos que o discurso de valorização das universidades públicas, talvez, tenha sido internalizado pelos jovens entrevistados.

Sobre o fato de o curso ser noturno, permitindo que trabalhassem e estudassem ao mesmo tempo, foram apontadas por Moisés (administrador, 28 anos), Clarice (economista, 26 anos) e Fernanda (economista, 27 anos) os quais já trabalhavam na área de serviços antes do ingresso na universidade. Desse modo, como as políticas de permanência, tais como o Programa Nacional de Assistência Estudantil (Decreto n. 7.234, 2010), por exemplo, não atingem plena efetividade, aqueles que pretendem trabalhar ao longo do curso buscam individualmente maneiras de possibilitar a integralização de seu curso de graduação, caso relatado no estudo de Vargas e Paula (2013). Um dos quesitos da permanência estudantil no ensino superior se refere ao transporte e à moradia, sendo que o que mais se repetiu nas falas foi a proximidade das casas e/ou do local de trabalho dos entrevistados com a universidade. Assim, reduziriam suas despesas com transporte e deslocamentos, especialmente por serem cursos noturnos nos quais geralmente o alunado trabalha e estuda, como apontado nas pesquisas de Sposito (1989), Furlani (2001), Bastos (2005), Mattos e Chaves (2010) e Vargas e Paula (2013).

Sobre a escolha profissional, os discursos dos entrevistados revelam dúvidas em relação às áreas de 
conhecimento pretendidas, assim como parecem lhes faltar informações sobre as universidades e os cursos oferecidos, sugerindo decisões tomadas de forma imediata, sem uma reflexão mais aprofundada sobre sua escolha profissional. Apesar da necessidade de se pensar a escolha profissional (Borges, 2017; Dias \& Soares, 2012), por meio da Orientação Profissional (OP), como no estudo de Bastos (2005), esse processo torna-se um artefato de "luxo" quando se observa a trajetória de jovens egressos do ensino médio público. Apenas uma das entrevistadas passou por um processo de OP em nossa investigação.

Ainda que as políticas de expansão do Governo Federal tenham ampliado o acesso às universidades públicas pelo REUNI (Decreto n. 6.096, 2007), interiorizando os campi, para os jovens aqui entrevistados, tanto a preparação para o Exame Vestibular quanto outros fatores determinantes da escolha profissional configuram-se como desafios a serem enfrentados em direção à universidade brasileira. Assim sendo, não basta ser aprovado, é preciso garantir a permanência na universidade até que se conclua a formação (Vargas \& Paula, 2013). Como afirma Administrador (nome fictício atribuído a um dos egressos formado em curso de Administração, 35 anos), "A universidade não foi tão, tão fácil assim pra sair não... (...) eu tive vários problemas que me tiravam da universidade".

Sobre o ingresso no campus, os jovens profissionais mencionaram seu percurso ao longo de sua formação em uma universidade que também estava em construção, considerando a inauguração do campus em prédio próprio somente ao final de suas graduações. Isto trouxe desafios a serem enfrentados pois, ao chegarem, não encontraram um campus universitário "pronto", mas um colégio alugado. Assim, havia uma sensação de improviso e, muitos questionavam se conseguiriam se formar antes do prédio "novo" ser inaugurado. Por outro lado, os jovens relataram que houve uma maior integração entre a comunidade universitária, principalmente, com os professores, fato este relatado, também, no estudo de Mattos e Chaves (2010). Ademais, foram destacadas as dificuldades em relação ao deslocamento entre suas casas e a universidade e, para aqueles que trabalhavam ou desenvolviam outras atividades no período matutino e vespertino, o deslocamento entre a casa, o trabalho e a universidade, bem como seu retorno para casa. São sobre essas condições que a PNAES (Decreto n. $7.234,2010)$ indica a intervenção para não só garantir a permanência universitária, mas realizá-la de modo desejável, o que ainda não acontece no ensino noturno.
Outro ponto relevante é que parece ocorrer ao longo das vivências universitárias uma oscilação de trabalhador-estudante e estudante-trabalhador em que esses encontram muito mais coerência nas práticas acadêmicas do que naquelas observadas no mercado de trabalho, apesar de o envolvimento com as atividades acadêmicas nem sempre possa ser tomado como mais próximo da situação do estudante-trabalhador.

Assim, ao concluírem seus cursos de graduação, os entrevistados indicaram sentimentos de liberdade, de conquista pelo fato de finalizar uma etapa importante de suas vidas. Aqueles que já trabalhavam efetivamente em organizações sentiram mais os efeitos da conciliação entre o trabalho e o término da graduação. Ainda que as trajetórias laborais dos jovens não sejam lineares, como bem apontaram Pais, Lacerda e Oliveira (2017), a universidade ainda pode ser considerada para os participantes desta pesquisa um marco em suas vidas, uma referência capaz de transformar suas concepções e sentimentos sobre o mundo e sobre si mesmos. O alongamento da escolarização (Mattos \& Bianchetti, 2011), finalmente, foi uma das formas de retorno à universidade planejada pelos recém-egressos. A premissa veiculada pela Teoria do Capital Humano de que a graduação em um curso de bacharelado "pro mercado competitivo é só uma graduação" (Carlos, economista, 24 anos) parece internalizada. Aqui também recorremos à discussão de Pochmann (2013) e de Pais, Lacerda e Oliveira (2017) quanto a essa relação entre formação no século XXI e a inserção no mercado de trabalho.

Logo, a universidade, apesar de constituir referência para todos os entrevistados, não foi suficiente para os jovens tornarem-se profissionais. Para efetivar a profissionalização, o jovem necessita, para além da esfera da formação, inserir-se no mercado de trabalho por meio dos atos de pertencimento entre as transações subjetiva/biográfica e objetiva/relacional (Bessa \& Franzói, 2017), ou por meio de uma rede de articulação entre a sua formação e a inserção, tal como mostra Silva (2010a). Ao findar a universidade, havia uma preocupação com a conquista desse espaço profissional.

\section{Trajetórias laborais e concepções sobre o trabalho}

Apresentamos conjuntamente os dois últimos Núcleos de Significação, pois pretendemos, a partir da narração das/pelas trajetórias laborais, analisar os movimentos laborais dos jovens profissionais em sua articulação com as concepções sobre o trabalho. Destacarmos que os sentidos atribuídos ao trabalho são evidenciados ao longo de todos os Núcleos de 
Significação, sendo as concepções ora apresentadas apenas sínteses na intenção de dar inteligibilidade aos discursos acerca do termo trabalho.

No período anterior à universidade, a maioria dos entrevistados não desenvolveu nenhuma atividade de trabalho remunerado, o que lhes possibilitou dedicação integral aos estudos. Tal decisão não derivou de uma decisão individual, mas da possibilidade de suas famílias custearem sua formação, como exemplificado no discurso de Vida (turismóloga, 24 anos): “[pais] sempre conversaram assim: olha, se dedica ao máximo que a gente vai fazer todo o possível pra você poder estudar, e não se preocupa em trabalhar".

No grupo que desenvolveu atividades laborais antes do período universitário, dois deles referiramse a atividades decorrentes do estágio desenvolvido no curso do ET; portanto, trabalho precoce, mas com caráter formativo. Quatro deles tiveram empregos cujos vínculos foram precários, geralmente com salários baixos. Alguns desses cargos foram de vendedor, auxiliar de serviços gerais e atendente de telemarketing. Esse resultado aproxima-se do que Silva (2010b) apontou sobre as experiências de trabalho no período da graduação de seus sujeitos de pesquisa, também egressos de uma IES.

Foi a partir do ingresso na universidade que os jovens buscaram uma inserção mais efetiva no mundo laboral. No caso desta investigação, as atividades desenvolvidas na graduação foram predominantemente acadêmicas, como estágios e programas trainee, como expressa Diego (administrador, 24 anos): “(...) não gostei muito do estágio, fui pro meu segundo estágio, não gostei do segundo estágio, fui pro terceiro estágio... gostei, mas... fui procurar outra empresa".

Após o término da universidade, apenas dois jovens encontravam-se sem nenhuma atividade remunerada quando entrevistados; uma jovem estava se preparando para prestar concursos públicos e outro buscando um emprego formal. Retomamos as palavras de Silva (2010a, p.257), pois convém esclarecer a inserção profissional de jovens graduados: "não se faz com rupturas, mas antes com continuidades e reencaminhamentos, a partir de determinadas estruturas previamente construídas e em constante reconstrução".

A análise dos discursos dos jovens entrevistados também revela a forte polarização entre dois campos: estudo e trabalho. Como antecipado, Foracchi (1977) evidenciou o esforço dispensado pelos jovens para conciliar a atuação nessas duas áreas, caracterizados por essa autora como estudantes que trabalham e trabalhadores que estudam. Carolina (administradora, 26 anos) resume esse tensionamento entre a educação e o trabalho: "foi um desafio também pra mim, que foi algo novo, só tava acostumada com a faculdade, só tava acostumada com, com o estudo, e aí eu me deparei com uma, uma situação bem diferente, trabalho é diferente". Mattos e Chaves (2010) também relatam situação parecida quando os jovens aprendizes entravam em contato com valores diferentes entre vida escolar e vida laboral.

Em relação aos projetos laborais, chamaram nossa atenção as contradições entre um futuro planejado e, ao mesmo tempo, incerto, como exemplifica o discurso de João (turismólogo, 25 anos) afirmando "vou ter que crescer bastante pra poder conciliar prazer com a minha qualidade de vida", mas apontando em relação ao futuro "um ponto de interrogação". Ao longo dos discursos dos entrevistados, quando esses falaram de suas expectativas profissionais, houve certa titubeação, assim como no estudo de Silva (2010b) quanto a graduados que foram bolsistas de iniciação científica. É possível que a esfera laboral seja organizadora das demais esferas da vida humana, o quanto o mundo do trabalho se articula com a dimensão subjetiva, por isso, como mencionaram Sato, Coutinho e Bernardo (2017, p. 13), só se torna possível "estudar a dimensão psicológica dos trabalhadores, a intersubjetividade e as relações interpessoais no trabalho situando-as concretamente nos contextos micro e macrossocial".

Finalmente, as concepções atribuídas ao trabalho foram diversificadas e múltiplas, de alguma forma, refletindo a própria heterogeneidade da classe trabalhadora e, por outro lado, uma homogeneidade das condições de trabalho, como afirmou Antunes (2014). Inicialmente houve uma certa dificuldade em falar sobre trabalho, como por exemplo, Larissa (administradora, 24 anos): "eu acho que eu nunca tinha parado pra pensar nisso". Mais adiante, foram mencionadas concepções sobre o trabalho que remetiam à necessidade financeira, do nível mais imediato da sobrevivência, do consumo e do sustento, assim como também foram suscitadas concepções de trabalho como transformação do próprio ser social: "o trabalho pra mim é o que eu sou, é quem eu sou" (Administrador, nome fictício atribuído a um dos egressos formado em Administração, 35 anos).

\section{Algumas considerações}

Ao findar nosso artigo, retomamos nosso objetivo de compreender as relações entre os movimentos laborais e os sentidos atribuídos ao trabalho por jovens profissionais, sendo uma resposta possível a consideração de que a construção dos processos de subjetivação, e dos movimentos laborais dos sujeitos concretos aqui entrevistados depende da mediação que esses estabelecem com a sociedade em que vivem. 
Logo, entendemos que os movimentos laborais partem das marcas sociais vivenciadas pelos jovens, das redes de relações sociais que estabelecem em suas vidas e parecem lançar os entrevistados em direção ao mundo do trabalho. Buscar um curso de graduação já se configura como um movimento laboral, pois ter cursado o ensino superior é considerado como um requisito (Pochmann, 2013) ou "passaporte facilitador" (Borges, 2017) para a entrada nesse disputado espaço. Dessa forma, empreendem esforços e escolhas profissionais, mas pautando-se em condições objetivas e subjetivas de efetivarem essas escolhas.

Outra análise decorrente de nossa investigação refere-se à correspondência entre os caminhos até então trilhados e as antecipações de futuro elaboradas. Procuramos conhecer como os jovens profissionais movimentam-se rumo à inserção profissional, sendo a principal característica dessa busca o distanciamento entre aquilo que esperavam encontrar no mercado de suas profissões e, o que encontraram depois de formados. Houve, logo, uma confrontação entre suas expectativas quando da busca por inserção laboral e suas atividades de trabalho efetivadas, o que também mediou novas concepções de trabalho para o grupo de jovens aqui investigados.

Finalmente, reconhecemos a impossibilidade de estudar longitudinalmente as trajetórias laborais em diferentes momentos daqueles que se movem, os "moventes", para retomarmos os termos de Bergson (2006). Portanto, para futuros estudos, sugerimos que possam ser realizadas entrevistas recorrentes com egressos da universidade, em diferentes momentos de seus percursos acadêmico e laboral.

Além disso, as transformações em curso, especialmente no que se refere ao crescimento do desemprego e as recentes alterações no que tange à legislação do trabalho e, ao mesmo tempo, uma diminuição da efetivação das políticas na área da Educação e Saúde, por exemplo, levam a um quadro bastante diferente da época em que pesquisamos. Nesse sentido, pesquisas que focalizem as trajetórias laborais em "tempos de crise" são fundamentais para entender as continuidades e rupturas nos processos de constituição dos sujeitos.

\section{Referências}

Aguiar, W. M. J. de \& Ozella, S. (2013). Apreensão dos sentidos: aprimorando a proposta dos núcleos de significação. Revista Brasileira de Estudos Pedagógicos, 94(236), 299-322. https://doi.org/10.1590/s217666812013000100015

Antunes, R. (2014). Desenhando a nova morfologia do trabalho no Brasil. Estudos Avançados, 28(81), 39-53. https://doi.org/10.1590/s0103-40142014000200004

Barbosa, M. L. de O. (1993). A sociologia das profissões: em torno da legitimidade de um objeto. BIB, 36, 3-30. (DOI INEXISTENTE)

Bastos, J. C. (2005). Efetivação de escolhas profissionais de jovens oriundos do ensino público: um olhar sobre suas trajetórias. Revista Brasileira de Orientação Profissional, 6(2), 31-43. https://doi.org/10.17771/pucrio. acad.32664

Bergson, H. (2006). O pensamento e o movente. (Bento Prado Júnior, Trad.). São Paulo, SP: Martins Fontes. (DOI INEXISTENTE)

Bessa, D. D. \& Franzói, N. L (2017). O preceito metodológico da ergologia e a análise de processos de identificação profissional. Ergologia, 18, 127-145. (DOI INEXISTENTE)

Borges, R. C. (2017). Juventudes: sentidos do trabalho e o processo de escolha profissional. In Lisboa, M. D. \& Soares, D. H. P. (Orgs.), Orientação Profissional em Ação: Formação e Prática de orientadores (pp. 207-226). São Paulo, SP: Summus. https://doi.org/10.11606/d.59.2009.tde-03082009-143254

Decreto n. 6.096, de 24 de abril de 2007. Institui o Programa de Apoio a Planos de Reestruturação e Expansão das Universidades Federais - REUNI. (2007). Brasília, DF: Ministério da Educação. https://doi.org/10.9771/gmed. v7i2.13078

Decreto n. 7.234, de 19 de julho de 2010. Dispõe sobre o Programa Nacional de Assistência Estudantil - PNAES. (2010). Brasília, DF: Presidência da República. https://doi.org/10.26512/2015.5.d.18619

Coutinho, M. (2009). Sentidos do trabalho contemporâneo: as trajetórias identitárias como estratégia de investigação. Cadernos de Psicologia Social do Trabalho, 12(2), 189-202. https://doi.org/10.11606/issn. 1981-0490.v12i2p189-202 
Dias, M. S. de L. \& Soares, D. H. P. (2012). A escolha profissional no direcionamento da carreira dos universitários. Psicologia: Ciência e Profissão, 32(2), 272-283. https://doi.org/10.1590/s1414-98932012000200002

Dubar, C. (1998). Trajetórias sociais e formas identitárias: alguns esclarecimentos conceituais e metodológicos. Educação \& Sociedade, 19(62), 13-30. https://doi.org/10.1590/s0101-73301998000100002

Foracchi, M. (1977). O estudante e a transformação da sociedade brasileira. São Paulo, SP: Biblioteca Universitária. (DOI INEXISTENTE)

Furlani, L. M. T. (2001). A claridade da noite: os alunos do ensino superior noturno (2 ${ }^{\mathrm{a}}$ ed.). São Paulo, SP: Cortez. https://doi.org/10.18222/eae02019992239

González Rey, F. (2013). Subjetividad, cultura e investigación cualitativa en psicología: la ciencia como producción culturalmente situada. Liminales. Escritos sobre psicología y sociedad, 1(4), 13-36. (DOI INEXISTENTE)

Lei n. 11.129, de 30 de junho de 2005. Institui o Programa Nacional de Inclusão de Jovens - ProJovem; cria o Conselho Nacional da Juventude - CNJ e a Secretaria Nacional de Juventude; altera as Leis ns. 10.683, de 28 de maio de 2003, e 10.429, de 24 de abril de 2002; e dá outras providências. (2005). Brasília, DF: Presidência da República. https://doi.org/10.17771/pucrio.acad.11064

Lei $n$. 12.852, de 5 de agosto de 2013. Estatuto da Juventude. (2013). Brasília, DF. (DOI INEXISTENTE)

Marx, K. (2010). Manuscritos econômicos-filosóficos. (Jesus Ranieri, Trad.). São Paulo, SP: Boitempo. (Originalmente publicado em 1844). (DOI INEXISTENTE)

Mattos, E. de \& Chaves, A. M. (2010). Trabalho e escola: é possível conciliar? A perspectiva de jovens aprendizes baianos. Psicologia Ciência e Profissão, 30(3), 540-555. https://doi.org/10.1590/s1414-98932010000300008

Mattos, V. de B. \& Bianchetti, L. (2011). Educação continuada: solução para o desemprego? Educação \& Sociedade, 32(117), 1167-1184. https://doi.org/10.1590/s0101-73302011000400015

Minayo, M. C. de S. (2008). O desafio do conhecimento: pesquisa qualitativa em saúde (11ā ed.). São Paulo: Hucitec. (DOI INEXISTENTE)

Pais, J. M., Lacerda, M. P. C. de, \& Oliveira, V. H. N. (2017). Juventudes contemporâneas, cotidiano e inquietações de pesquisadores em Educação - uma entrevista com José Machado Pais. Educar em Revista, 64, 301-313. https://doi.org/10.1590/0104-4060.50119

Pochmann, Márcio (2013). Juventudes na transição para a sociedade pós-industrial. In Macambira, J. \& Andrade, F. R. B. (Orgs.), Trabalho e formação profissional: juventudes em transição (pp. 37-56). Fortaleza, CE: IDT, UECE, BNB. https://doi.org/10.11606/d.48.2010.tde-31082010-095830

Sato, L. (2013). Recuperando o tempo perdido: a psicologia e o trabalho não regulado. Cadernos de Psicologia Social do Trabalho, 16(spe1), 99-110. https://doi.org/10.11606/issn.1981-0490.v16ispe1p99-110

Sato, L., Coutinho, M. C., \& Bernardo, M. H. (2017). A perspectiva da psicologia social do trabalho. In Coutinho, M. C., Bernardo, M. H., \& Sato, L. (Orgs.), Psicologia Social do Trabalho (pp. 11-24). Petrópolis, RJ: Editora Vozes. https://doi.org/10.1590/1982-02752017000100001a

Silva, M. M. da. (2010a). Redes de relações sociais e acesso ao emprego entre os jovens: o discurso da meritocracia em questão. Educação \& Sociedade, 31(110), 243-260. https://doi.org/10.1590/s0101-73302010000100013

Silva, M. M. da. (2010b). Estratégias de sobrevivência: Bolsa de Iniciação Científica, desemprego e precarização entre os jovens. Teoria e Prática da Educação, 13(3), 87-98.

Silva, M. M. da. (2014). Inserção Profissional de jovens: o circuito fechado da precarização. Trabalho \& Educação (UFMG), 23(3), 177-194. (DOI INEXISTENTE)

Sposito, M. P. (Coord.). (1989). O trabalhador-estudante: um perfil do aluno do curso superior noturno. São Paulo: Edições Loyola. https://doi.org/10.11606/d.74.2018.tde-20062018-140532

Vargas, H. M., \& Paula, M. de F. C. de. (2013). A inclusão do estudante-trabalhador e do trabalhador-estudante na educação superior: desafio público a ser enfrentado. Avaliação: Revista da Avaliação da Educação Superior, 18(2), 459-485. https://doi.org/10.1590/s1414-40772013000200012

Vigotsky, L. S. (2007). A formação social da mente: o desenvolvimento dos processos psicológicos superiores. (José Cipolla Neto, Luís Silveira Menna Barreto e Solange Castro Afeche, Trad.). (7ạ ed.). São Paulo, SP: Martins Fontes. (Originalmente publicado em 1930). (DOI INEXISTENTE) 
Zago, N. (2006). Do acesso à permanência no ensino superior: percursos de estudantes universitários de camadas populares. Revista Brasileira de Educação, 11(32), 226-237. https://doi.org/10.1590/s1413-24782006000200003

\section{Dados dos autores:}

Geruza Tavares D’Avila - Doutorado, Universidade Federal do Rio Grande.

Maria Chalfin Coutinho - Pós-Doutorado, Universidade Federal de Santa Catarina.

Especificação de autoria:

$\mathrm{O}$ artigo foi escrito a partir da tese da autora sob orientação da segunda autora e foi sendo construído conjuntamente.

Endereço para correspondência:

Geruza D'Avila

Av. Itália, $\mathrm{km} 8$ - Bairro Carreiros

96203-000, Rio Grande, RS, Brasil

E-mail: geruzad@yahoo.com.br

Recebido em: 11/01/2018

Aceito em: 06/12/2018.

Publicado em: 05/08/2019. 